University of Warwick institutional repository

This paper is made available online in accordance with

publisher policies. Please scroll down to view the document

itself. Please refer to the repository record for this item and our

policy information available from the repository home page for further information.

To see the final version of this paper please visit the publisher's website. Access to the published version may require a subscription.

Author(s): C A Hawley, N D Galbraith and V A deSouza

Article Title: Medical education on fitness to drive: a survey of all UK medical schools

Year of publication: 2008

Link to published version :

http://dx.doi.org/ 10.1136/pgmj.2008.067959

Publisher statement: none 


\section{Medical education on fitness to drive: a survey of all UK medical schools}

C A Hawley, N D Galbraith and V A deSouza

Postgrad. Med. J. 2008;84;635-638

doi:10.1136/pgmj.2008.067959

Updated information and services can be found at:

http://pmj.bmj.com/cgi/content/full/84/998/635

These include:

References This article cites 9 articles, 5 of which can be accessed free at:

http://pmj.bmj.com/cgi/content/full/84/998/635\#BIBL

Rapid responses You can respond to this article at:

http://pmj.bmj.com/cgi/eletter-submit/84/998/635

Email alerting Receive free email alerts when new articles cite this article - sign up in the box at service the top right corner of the article

Notes

To order reprints of this article go to:

http://journals.bmj.com/cgi/reprintform

To subscribe to Postgraduate Medical Journal go to:

http://journals.bmj.com/subscriptions/ 


\title{
Medical education on fitness to drive: a survey of all UK medical schools
}

\author{
C A Hawley, ${ }^{1}$ N D Galbraith, ${ }^{2}$ V A deSouza ${ }^{3}$
}

\section{See Editorial, p 617}

- Appendix is published online only at http://postgradmedj. com/content/vol84/issue998

${ }^{1}$ Health Sciences Research Institute, Warwick Medical

School, University of Warwick, Coventry, UK; ${ }^{2}$ Applied

Research Centre in Health and

Lifestyle Interventions, Coventry

University, Coventry, UK ;

${ }^{3}$ Department of Public Health,

Health Service Executive West

(Mid Western Area), Limerick,

Eire

Correspondence to:

Dr C A Hawley, Health Sciences

Research Institute, Warwick

Medical School, University of

Warwick, Coventry, CV4 7AL,

UK; c.a.hawley@warwick.ac.uk

Received 17 January 2008

Accepted 5 May 2008

\section{ABSTRACT}

Aim: To identify the extent to which medical aspects of fitness to drive (FTD) are taught within UK medical schools.

Methods: A survey of all 32 UK medical schools. Indepth interviews with a range of staff at two medical schools; telephone survey of 30 schools.

Results: Two thirds of schools reported specific teaching on medical aspects of FTD but few covered it in any depth or in relation to specific medical conditions. Only one school taught FTD in relation to elderly medicine. FTD was an examination topic at only 12 schools.

Conclusion: Teaching on FTD is inconsistent across UK medical schools. Many new doctors will graduate with limited knowledge of medical aspects of FTD.

There are a number of medical conditions which may have a significant impact on the ability to drive, including neurological, cardiovascular and psychiatric disorders and diabetes. ${ }^{1}$ In addition, elderly drivers form an important subgroup of potentially at-risk drivers as morbidity increases with age. ${ }^{2}$ However, previous studies have suggested a lack of knowledge among doctors regarding the FTD of their patients. ${ }^{3-6}$ King et al surveyed hospital doctors and general practitioners to assess knowledge of the laws and recommendations regarding FTD for particular medical conditions. ${ }^{7}$ They found that doctors had poor basic knowledge of FTD, concluding that this topic should receive more attention in undergraduate and postgraduate medical education. Morgan found that junior doctors tended to have a poor understanding of General Medical Council (GMC) guidelines regarding patient confidentiality and of general driving regulations. ${ }^{8}$ More recently, Ormerod and Heafield reported that knowledge of FTD among the medical profession and medical students remains inadequate. ${ }^{9}$ In Israel, Steier et al also reported poor awareness of the medical restrictions on FTD among physicians, recommending that FTD be included in medical education programmes. ${ }^{10}$

The UK Department for Transport (DfT) is aware that doctors do not routinely advise patients of how their medical condition may affect driving fitness or of their obligation to notify the Driver and Vehicle Licensing Agency (DVLA) regarding certain conditions. Consequently, as part of a larger study commissioned by the DfT into the knowledge of health professionals regarding FTD, all UK medical schools were surveyed to examine the extent of tuition on this topic. The objectives of this study were to identify whether UK medical schools offer specific teaching on FTD, if it is examined, and to determine whether there is uniformity of teaching across schools.

\section{METHODS}

A survey of all UK medical schools was carried out throughout 2005 and 2006.

\section{Questionnaire development}

A structured questionnaire was devised using the results of a qualitative study conducted at two medical schools, one long established and one newly established. A synopsis of information from the qualitative survey is shown in box 1. The questionnaire (supplemental appendix 1) incorporated a number of open ended questions and covered the inclusion of medical aspects of FTD in the curriculum; areas or modules where FTD was specifically taught; when it was taught; and whether it was examined.

\section{Participants}

All 32 UK medical schools were involved. Of these,19 schools were established before 1975 and deemed "older"; the 13 established after 1975 were "newer" schools.

The websites of each medical school were used to identify staff with a senior managerial or coordinating role within medical education. These personnel were contacted in order to determine the most appropriate person to interview regarding the school curriculum. Potential interviewees were then telephoned to either conduct the short interview there and then or to arrange a suitable time for future interview. Telephone interviews were conducted by researchers (NG and VdS) using the questionnaire. Questions were mostly open ended and interviewees were asked to expand on their answers where appropriate.

\section{Data analysis}

The data were analysed using SPSS v.14. Frequency counts were used to measure teaching and examination of FTD within modules and medical specialties. The $\chi^{2}$ test was used to compare tuition and examination of FTD between old and new medical schools.

\section{RESULTS}

Personnel at all 32 UK medical schools were interviewed. Full details of the curriculum were not available for all schools. At the time of the survey, some of the newer medical schools (Brighton and Sussex, Hull-York, and Swansea) had not yet developed the curriculum for the final 


\section{Box 1: Qualitative study}

In 2005, an in-depth study was carried out in one long established medical school (Birmingham) and one newly established medical school (Warwick). Using information taken from the respective medical school websites, those having a senior management/coordination role for the undergraduate medical course were contacted. Typically the role would be that of Dean, Course Co-ordinator, Course Director and/or Director of Medical Education. All interviews were conducted by telephone using a semi-structured interview schedule. Interviewees were asked if fitness to drive (FTD) was covered in undergraduate medical training and teaching and if so, the extent to which it was covered and the methods used to teach it. Following these interviews, teaching leaders in five specific areas (cardiovascular medicine; elderly medicine; diabetes; neurology; and psychiatry) were also interviewed. Tuition and teaching on FTD was reported as follows:

\section{Medical school 1 (established)}

FTD taught in modules on:

- Medical ethics and law (routinely taught and examined)

- Cardiovascular medicine (routinely taught, sometimes examined)

- Neurology/epilepsy (routinely taught, sometimes examined)

FTD not taught or examined:

- Diabetes

- Psychiatry

- Elderly medicine

FTD taught during clinical placements-dependent upon clinical cases encountered

Students receive training on FTD in years 1 and 2 on patient confidentiality and are given copies of the GMC guidelines on confidentiality issues and DVLA guidelines on medical aspects of fitness to drive

\section{Medical school 2 (new)}

FTD taught in modules on:

- Diabetes (routinely taught, possibly examined)

- Neurology/epilepsy (routinely taught, sometimes examined)

- Clinical pharmacology (sometimes taught, not examined)

- Social science (sometimes taught, not examined)

- Neurobiology (sometimes taught, not examined)

FTD not taught or examined:

- Cardiovascular medicine

- Psychiatry

- Elderly medicine

FTD taught during clinical placements-dependent upon clinical cases encountered

degree years. Two medical schools (Durham and St Andrews) taught undergraduates during the early part of medical training, with the final years of their course being completed elsewhere.

Of the 32 medical schools, $21(65.6 \%)$ reported specific teaching on medical aspects of FTD within their curriculum. In an open ended question, interviewees were asked to outline the topic areas or specific modules in which FTD would be covered. Across the 32 schools, a wide range of areas or modules which may include FTD teaching were reported (fig 1). Those areas most likely to involve FTD were: neurology, particularly in
Figure 1 Topic areas where fitness to drive is taught and number of medical schools offering tuition in each area.

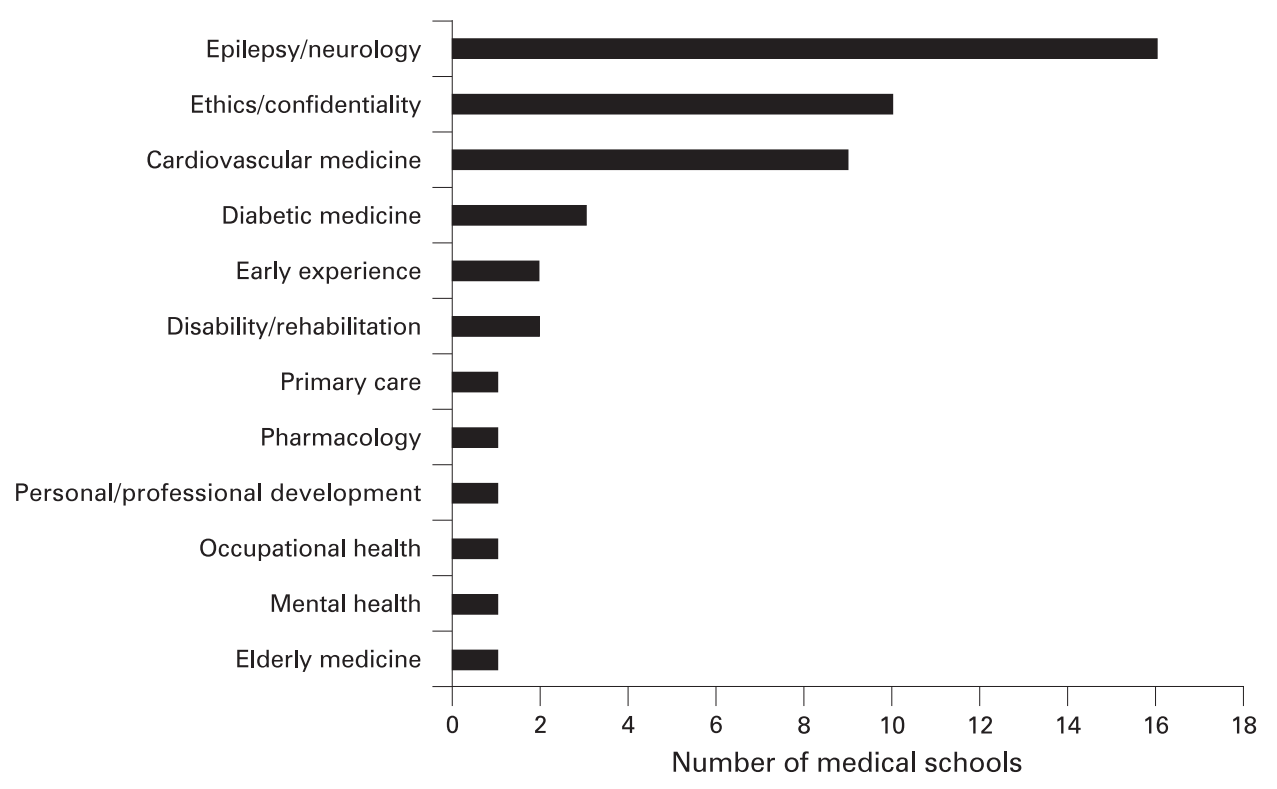


Table 1 The teaching of fitness to drive (FTD) in relation to specific topic areas

\begin{tabular}{llll}
\hline Topic & $\begin{array}{l}\text { FTD taught } \\
\text { (number of } \\
\text { schools) }\end{array}$ & $\begin{array}{l}\text { FTD possibly } \\
\text { taught (number } \\
\text { of schools) }\end{array}$ & $\begin{array}{l}\text { FTD not taught } \\
\text { (number of } \\
\text { schools) }\end{array}$ \\
\hline Elderly care & 1 & 1 & 30 \\
Diabetes & 3 & 1 & 28 \\
Cardiovascular & 9 & 2 & 21 \\
Psychiatric & 3 & 2 & 27 \\
Neurological & 15 & 2 & 15 \\
\hline
\end{tabular}

relation to epilepsy; medical ethics and patient confidentiality; and cardiovascular medicine. Least likely were elderly medicine; mental health; and occupational health. Only 10 medical schools taught FTD in relation to two or more topic areas.

Interviewees from all medical schools were then specifically asked if tuition on FTD was provided in relation to five key areas: neurology; cardiovascular medicine; diabetes; psychiatry; and elderly medicine (table 1).

Of the schools offering FTD tuition, most were unable to quantify the extent to which FTD was taught and only four schools gave a specific number of lectures or tutorials. Three of these schools reported just one lecture, the fourth reported one lecture and one tutorial. Only five schools claimed to offer teaching of FTD in any great depth. Twelve schools (38\%) reported that they included FTD in examinations, although seven others suggested that FTD could possibly be an examination topic. The academic year in which these examinations might occur varied between schools.

Three-quarters of "older" (pre-1975) schools (14) offered some specific teaching on FTD compared to half of the "newer" schools (7), but this difference was not significant. There were no differences with regard to examination of FTD.

\section{DISCUSSION}

There was wide variation in the depth and breadth of teaching on FTD across medical schools. Only 21 of the 32 schools offered any specific FTD tuition to medical students. The majority of schools reported some teaching of FTD through self guided study, lectures/tutorials and/or clinical placements. However, only four schools were able to quantify the extent of FTD tuition, and for many schools FTD coverage was reported to be brief, inconsistent, or impossible to determine. One third of medical schools examined students on FTD issues.

Previous research has consistently reported poor awareness of medical aspects of FTD among medical practitioners, and investigators have called for FTD to be included in medical training..$^{7-9}$ The findings of the present study suggest that most medical students do not receive routine training on FTD at medical school and that newly qualified doctors will continue to have limited knowledge of FTD.

Appropriate education of doctors on medical aspects of FTD and DVLA guidelines is in the interests of both patients and doctors. GMC guidelines state that it is a doctor's duty to advise patients whose FTD is in doubt, ${ }^{11}$ and King et al highlight that doctors should be aware that they could be liable for prosecution if they fail to advise their patients accordingly? The UK licensing system is dependent upon the driver's self declaration of any medical condition which can adversely affect

\section{What is already known on the subject}

- Department for Transport figures show that $72 \%$ of the adult population hold a driving licence.

- Medical practitioners have poor knowledge of the Driver and Vehicle Licensing Agency (DVLA) medical rules on fitness to drive (FTD), and previous research has shown that patients are not routinely advised about how their medical condition may impair their driving.

\section{What this study adds}

- UK medical schools offer varying degrees of tuition on medical aspects of fitness to drive.

- In most schools, FTD is not taught in relation to specific medical conditions or in relation to elderly medicine.

- Medical aspects of FTD are examined by approximately one third of schools.

- Newly qualified doctors will differ in their knowledge of FTD depending upon where they were taught and the medical cases they encountered during clinical placements.

FTD, and it is therefore good practice for doctors to alert patients if their medical condition could affect driving. A recent DfT publication provides a useful list of medical conditions which are "clinical red flags" for potentially impaired driving. ${ }^{12}$

In the UK, there are currently over 33 million driving licence holders, and the proportion of older drivers is increasing. ${ }^{13}$ In the over 70 age group, $50 \%$ now hold a driving licence compared to $15 \%$ in 1975 . However, only one medical school claimed to cover FTD issues within the field of elderly medicine. While old age is not in itself a bar to safe driving, the prevalence of medical conditions which can affect FTD is higher among older people. ${ }^{10}$ It is therefore recommended that issues relating to FTD are taught within the specialty of elderly medicine.

\section{Limitations}

There are difficulties in gaining an accurate assessment of the coverage of FTD for each medical school. The staff we interviewed were those who, according to course managers and coordinators, were best able to address our questions. However, even these individuals might not have complete knowledge of the curriculum. As was highlighted by some schools, much of students' learning is self driven or independent from the planned course content. It was also difficult to quantify the extent to which FTD might be covered in clinical placements. However, where staff were unsure, they mostly suspected that FTD coverage was not extensive. This suggests that FTD is of low priority for many medical schools, as indicated by the few schools which examine students on this topic.

Future work should be directed towards harmonising FTD tuition and examination across all medical schools.

\section{Conclusions}

Although the 1992 King study called for improvements in medical education, our own survey found that medical training on FTD remains inadequate. We suggest that this important 
issue receives universal coverage by UK medical schools, as knowledge of FTD among new doctors appears to be dependent upon the school they attended and the nature of their clinical placements.

Acknowledgements: The authors thank the representatives of each medical school for their kind cooperation.

$\mathrm{CH}$ designed and led the study, analysed and interpreted data and wrote the paper. $\mathrm{NG}$ and VdS were involved in collecting, analysing and interpreting data. Lynda Lavery collected additional data. $\mathrm{CH}$ is guarantor.

Funding: This study was commissioned and funded by the Department for Transport (DfT). The findings and recommendations are those of the authors and do not necessarily represent the views of the DfT.

Competing interests: None.

\section{REFERENCES}

1. Driver and Vehicle Licensing Agency. For medical practitioners: at a glance guide to the current medical standards of fitness to drive. Swansea: DVLA, 2008.

2. Morgan R, King D. The older driver - a review. Postgrad Med J 1995;71:525-8.
3. Fischer BM, Storer AM, Frier BM. Diabetes, driving and the general practitioner. BMJ (Clin Res Ed) 1985;291:181-2.

4. Wise MEJ, Watson JP. Postal survey of psychiatrists' knowledge and attitudes towards driving and mental illness. Psychiatric Bull 2001:25:345-9.

5. Hitchen L. Doctors are failing to tell diabetic people about UK driving rules. BMJ 2006;332:812.

6. O'Neill D, Crosby T, Shaw A, et al. Fitness to drive and the older patient: awareness among hospital physicians. Lancet 1994;344:1366-7.

7. King D, Benbow SJ, Barrett JA. The law and medical fitness to drive - a study of doctors' knowledge. Postgrad Med J 1992;68:624-8.

8. Morgan JF. DVLA and GMC guidelines on 'fitness to drive' and psychiatric disorders: knowledge following an educational campaign. Med Sci Law 1998;38:28-33.

9. Ormerod S, Heafield MTE. Medical restrictions to driving: awareness of patients and doctors. Postgrad Med J 2007; 76:523.

10. Steier TS, Kitae E, Wiener A, et al. Are medical reports on fitness to drive trustworthy? Postgrad Med J 2003;79:52-4.

11. General Medical Council. Disclosure to protect the patient or others. Para 27. Confidentiality: Protecting and Providing Information. 2004. www.gmc-uk.org/ guidance/library/confidentiality-fac.asp (Accessed December 2007).

12. Carter T. Fitness to drive: a guide for health professionals. London: Royal Society of Medicine Press, 2006.

13. Department for Transport. Transport statistics bulletin: national travel survey 2006. London: Transport Statistics, 2007.

\section{Ouality \& Safety in Health Care}

Quality \& Safety in Health Care is a leading international peer-review journal in the growing area of quality and safety improvement. It provides essential information for those wanting to reduce harm and improve patient safety and the quality of care. The journal reports and reflects research, improvement initiatives and viewpoints and other discursive papers relevant to these crucial aims with contributions from researchers, clinical professionals and managers and experts in organisational development and behaviour.

qshc.bmj.com 